\title{
НЕКОТОРЫЕ ПРАВОВЫЕ ПРОБЛЕМЫ РАВЕНСТВА РЕЛИГИОЗНЫХ ОБРАЗОВАНИЙ ПЕРЕД ЗАКОНОМ: СРАВНИТЕЛЬНЫЙ АНАЛИЗ
}

\author{
ГАСАНОВ Симран Сейфаддин оглы - кандидат юридических наук, \\ преподаватель кафедры Гражданского права юридического факультета \\ Бакинского государственного университета
}

DOI:10.32782/EP.2020.1.21

УДК 342.724

\begin{abstract}
В статье рассматривается практика международного и национального законодательства о равенстве религиозных образований перед законом, а также связаннъе с этим научно-теоретические исследования. Автор на основе сравнительного анализа соответствуюших нормативно-правовъхх актов Азербайджанской Республики (АР) и некоторъхх зарубежнъх стран анализирует особенности бормально-правового равенства религиозньхх образований, обращая особое внимание на отдельные моменты, препятствующие обеспечению такого равенства. Обосновъивается невозможность и бесполезность обеспечения бактического равенства религиозных образований, проводится поиск путей въихода из проблем, связанных с разнылми подходами государства к различнылм религиям и их институииональным структурам. Особое внимание уделяется широко применяемой в юридической практике, поддержке титульных религий на основе различных классификаций. Отмечается отсутствие единой позииии в научно-теоретическом анализе указанных проблем. В заключение вносятся конкретные предложения по обеспечению максимального бормально-правового равенства религиознъгх образований и предотвращению дискриминации в их отношении.

Ключевъе слова: религиознъие образования, религиозная дискриминация, бормальное равенство, публичнъе юридические лица, традииионнве религии, государственная религия.
\end{abstract}

\section{Введение}

Глобальные миграционные процессы обусловили реальность совместного проживания людей, принадлежащих различным религиозным и этническим группам в пределах единого политико-социального пространства. В такой ситуации обеспечение государством равного отношенияк существующим в стране религиям и религиозным образованиям, приобретает большое значение, как минимум, с формально-правовой точки зрения. Однакос уверенностью можно сказать, что ни в законодательной практике, ни в соответствующих научно-теоретических исследовательских работах единого подхода, связанного с этим принципиальным моментом, не наблюдается. Несмотря на закрепление в большинстве правовых систем положений о равенстве религий и религиозных образований перед законом, а также о недопустимости дискриминации по отношению к ним, на практике, религии, исповедуемые большинством населения данной страны, получают преимущества законодательством в той или иной форме, устанавливаются различные льготы и привилегии для их институциональных структур.В связи с этим, по нашему мнению, было бы полезным обратить внимание на богатый законодательный опыт многоконфессионального и многонационального Азербайджана, как места, известного своим мультикультурализмом и толерантностью, расположенного на стыке разных культур, 


\section{Цивільне, підприсмницьке, господарське та трудове право}

и в свете соответствующих научно-теоретических подходов провести сравнительный анализ этого опыта с аналогичными нормативно-правовыми актами некоторых секулярных стран и выдвинуть некоторые конкретные предложения.

Социальная и официальная религиозная дискриминация. Прежде всего следует отметить, что многие исследователи, рассматривая теоретические основы религиозной дискриминации, являющейся одной из основных угроз для толерантности и мультикультурной среды, различают две их разновидности: социальная религиозная дискриминация - дискриминационные и насильственные действия в отношении религиозных меньшинств со стороны негосударственных структур и групп общества [31] и религиозная дискриминация на государственном уровне - ограничения на деятельность религиозных меньшинств, налагаемые государством и не применяемые к религиозному большинству [28, с. 19]. Действительно, положение различных этнических и религиозных групп в стране в значительной степени зависит также и от отношения к таким группам со стороны общества в целом, в том числе со стороны народа, составляющего численное большинство, и от представляемой им религии. Можно со всей уверенностью сказать, что толерантность и уважение к различным культурам являются одновременно исторически сложившимися национально-духовными богатствами азербайджанцев, так и одними из основных ценностей ислама. Эти обстоятельства влияют и на формирование соответствующего законодательства.

Равенство религиозных образований в международном и национахьном законодательстве. Учитывающие повышенную чувствительность религиозных вопросов международные структуры постоянно держат в центре внимания проблемы, связанные с их равенством. Во многих международных документах, прямо или косвенно касающихся вопросов религиозного равенства, религиозная дискриминация считается грубым нарушением прав и свобод человека, а ведение серьезной борьбы с такими проявлениями закрепляется как обязанность государства. «Декларация о ликвидации всех форм нетерпимости и дискриминации на основе религии или убеждений» четко определяет правовое понятие нетерпимости и дискриминации на основе религии или убеждений и устанавливает, что все государства прилагают необходимые усилия по принятию или отмене законодательства, когда это необходимо для запрещения любой подобной дискриминации, а также для принятия всех соответствующих мер по борьбе против нетерпимости на основе религии или иных убеждений в данной области (ст. 4.2) [3].

Азербайджанское государство, как политическая структура, обязанная обеспечить равную защиту законных интересов всех слоев общества, также стремится соблюдать принцип равного подхода в религиозных вопросах, требующих чрезвычайную чувствительность и внимательность. Исходя из этой необходимости, Конституция страны закрепляет положение о равенстве всех религий перед законом (пункт I статьи 18) [15]. Подобная редакция, также встречающаяся в основных законах многих стран, на наш взгляд, является некорректной. Было бы целесообразным, если бы такое равенство относилось к субъектам права, религиозным организациям или верующим, а не к «религиям», лишенным достаточно конкретных легальных критериев. Возможно, именно по этой причине в Законе АР «О свободе вероисповедания» (3СВ) [7] закреплено положение о равенстве перед законом не только религий, но и религиозных образований $(3 \mathrm{CB}$, статья 5, часть 3). Отметим, что в Конституции Российской Федерации (РФ) также закреплено положение о равенстве перед законом именно "религиозных объединений», а не религий (пункт 2 статьи 14) [20].

В 3СВ, в соответствии с принципом равенства перед законом, также закреплено конкретное положение, направленное на обеспечение равенства всех религиозных образований перед законом, гласящее, что в отношении какой бы то ни было религии (религиозного течения) и религиозного образования не могут быть установлены те или иные преимущества или ограничения 
по сравнению с другими. (ЗСВ - Статья 5, часть 3, второе предложение). Следует учитывать, что:

во-первых, равенство перед законом не означает фактического равенства. Как справедливо отмечает один автор, «формальное равенство выражается в возможностях и условиях, создаваемых государством для людей. Государство должно создать равные возможности и условия для всех. В дальнейшем кто-то, более успешно пользуясь созданными для всех возможностями, прогрессирует в какой-либо сфере деятельности, что, понятно, приведет к фактическому неравенству» [35, с.144].Вышесказанное целиком и полностью может быть применено также к правовому статусу религиозных организаций. Обеспечение их фактического равенства сложное и, по нашему мнению, бесполезное дело. Әти образования не могут быть равны по таким показателям, как количество членов, финансовое положение, заслуги в историческом становлении и развитии государственности и национального самосознания и т.д. Негосударственные институты, общественные объединения, профсоюзы, различные группы населения и отдельные граждане могут свободно сотрудничать, поддерживать и вступать в гражданско-правовые отношения с тем или иным религиозным образованием. В этом случае предпочтение какой-либо религии не должно считаться дискриминацией и нарушением закона;

во-вторых, если ограничения или льготы применяются в равной степени ко всем религиям (религиозным течениям), то установление таких норм не противоречит принципу равного отношения и не должно оцениваться как дискриминация или привилегия;

в-третьих, если разные права и обязанности и различная правоспособность религиозных образований исходят от их мест в иерархической структуре конфессиональной системы, то данное обстоятельство не может рассматриваться как неравенство, поскольку такая разница определяется, в основном, внутренними правилами религиозных конфессий и применяется к ор- ганизациям, находящимся на одной и той же ступени системы религиозных образований.

Научно-теоретические дискуссии о формальном равенстве религиозных организаций. Поскольку роль религий и их институциональных объединений в историческом и культурном развитии страны, их функции в обществе, продолжительность их существования, количество и состав их последователей далеко не одинаковы, научно-теоретические подходы к их формально-правовому равенству также весьма далеки от схожести. Так, в доктрине широко распространены соображения о возможности и целесообразности применения формального равенства не ко всем конфессиям, а только к религиям, исповедуемым большинством населения страны [см. 23, с.52; 26; 25; 4].

Некоторые ученые и религиозные деятели идут еще дальше, полагая, что государство обязано защищать свое «духовное пространство», сформировавшееся на протяжении многих веков [21, с.34], не проявлять религиозный нейтралитет [27, с.39], выполняя своего рода функции «контролера», не должно допускать проникновение вновь появившихся и развивающихся религиозных течений в канонические территории «традиционных» конфессий [24]. Конечно, трудно согласиться с такими радикальными предложениями, противоречащими нормам международного права и ставящими различные религиозные конфессии в явно неравное положение перед законом. Определение того, какие из новых религиозных течений являются «полезными», а какие - «вредными» для общества, абсолютно не соответствует функциям демократического и правового государства.

Классификации, являющиеся причиной дискриминации. Исследования показали, что, хотя прямое запрещение появления новых религиозных учений, течений, групп и образований не представляется возможным, тем не менее, многие государства, законодательно классифицируя существующие в данной стране религии под разными названиями: «государственные», 


\section{Цивільне, підприємницьке, господарське та трудове право}

«негосударственные», «традиционные», «нетрадиционные», «публичные», «частные» и т.д., стараются преимущественно поддерживать так называемые титульные религии, укоренившиеся в обществе и исповедуемые большинством населения страны. В результате такого разделения обеспечение даже формального их равенства до конца является довольно проблематичным вопросом.

Согласно исследованию, проведенному Гарвардским университетом в 2000 году в 188 странах, 75 стран-участниц данного исследования объявили ту или иную религию своей официальной государственной религией [34] (за прошедший период, существенных изменений в данной статистике не произошло). Норман Доу, известный профессор права Кардиффского Университета, считает, что данный тип отношений между религией и государством является моделью «государственной церкви». По его мнению, в данном случае «существует тесная конституционная связь между государством и конкретной национальной или народной церковью» [33, с.88]. Например, Конституция Греции считает Христианскую Восточно-Православную Церковь «господствующей религией» Греции (ст.3.1) [16], Конституция Норвегии закрепляет Евангелическо-Аютеранскую церковь в качестве «официальной государственной религией, поддерживаемой государством» (параграф 2) [18], согласно Конституции Исландии, ЕвангелическоЛютеранская церковь является «государственной церковью, пользующейся поддержкой и покровительством государства» (ст.62) [17]. Вполне естественно, что в дальнейшем такие декларативные положения находят свое продолжение в качестве дополнительных привилегий и льгот в конкретных законодательных актах. Следует отметить, что в основных законах АР и РФ такие нормы не установлены.

Одна из классификаций, которая может привести к закреплению предпочтительного правового статуса той или иной религии (религий) и установлению для неё (них) привилегий и льгот, является группирование религий и религиозных орга- низации под названием «традиционные и нетрадиционные». Например, Конституция Литвы (ст. 43) предусматривает, что “государство признает традиционные в Аитве церкви и религиозные организации в случае, если они имеют опору в обществе и их учение и обряды не притоворечат закону и нравственности» [19] и соответствующим законодательством утверждается закрытый список таких религий [8]. Соответствующее законодательство Сербии делит существовавшие в стране на протяжении многих веков религиозные организации на две группы: традиционные христианские церкви и традиционные религиозные общины мусульман и евреев [13]. В последние годы заметно обострились теоретические дебаты вокруг такой классификации религий $[24 ; 14 ; 1 ; 32]$. В действительности, данная классификация относится только лишь к религиоведению, и, на наш взгляд, было бы ошибочным вынесение этого вопроса в правовую плоскость. В связи с этим вопросом нам видится более справедливым для применения в теории подход И.Я.Кантерова, утверждающего, что существующие на протяжении многих веков христианство, ислам, иудаизм и буддизм следует рассматривать как традиционные религии, а учения, которые в корне отличаются от этих религий - как нетрадиционные религии [14, с.472].

Публичные и частные религиозные организации. Еще одна «легальная классификация», представляющая собой серьезную угрозу формальному равенству религиозных организаций, состоит в отнесении их к субъектам частного или общего (публичного) права. Согласно указанной классификации, сторонником которой является также известный эксперт Коул Драм, частные религиозные организации существуют на «базовом уровне», а общие (публичные) религиозные организации в «высшей организационной форме». Подобное разделение указанный автор признает нормальным при условии, если это не противоречит принципу равенства религиозных структур перед законом [30, c.18]. Публичные религиозные организации выделяются Конституцией Герма- 
нии («если их устав и количество членов служат гарантом продолжительности их существования»)(ст. 137.5) [22]; Законом Румынии «Об общем статусе религиозных свобод и вероисповеданий (культов)» (по количеству последователей в соответствии с результатами переписи населения [12]; Гражданским кодексом Грузии, («религиозное течение, имеющее исторические связи с Грузией, или религиозное течение, законодательством признанное религией в странах - членах Совета Европы») [2]. Положения о дифференциации государственных (публичных) религиозных организаций закреплены также в Австрийских Законах «О статусе корпораций» и «б общественных объединениях» [6].

На наш взгляд, независимо от законодательного уровня декларирования формального равенства религиозных организаций, обеспечение указанного требования в странах с вышеуказанной классификацией не представляется возможным по причине их (религиозных образований) юридической принадлежности. Действительно, законодательством этих государств, как правило, предусматриваются существенные привилегии для публичных религиозных организаций, в том числе нормы, связанные с представлением налоговых льгот, учреждением школ, финансированием или субсидированием из государственного бюджета, участием в государственных мероприятиях и в процессе религиозного образования в государственных школах, закладкой кладбищ, получением заработной платы от государства для своих религиозных деятелей, платным руководством проведения религиозных обрядов и ритуалов в воинских частях, пенитенциарных учреждениях, больницах, школах и в других местах, пользованием другими правами.

Согласно законодательству АР, все религиозные организации, имеющиеся в стране, так же сгруппированы в две основные группы: немусульманские религиозные общины и мусульманские религиозные общины, в отношении которых установлен ряд императивно-организационных правил. Так, в соответствии с нормами 3СВ, мусульманские религиозные органи- зации в АР объединяются в своем историческом религиозном центре - Управлении Мусульман Кавказа (УМК), по организационным вопросам подчинены указанному Управлению и отчитываются перед ним о своей деятельности. Являясь чисто организационно-иерархическими, данные положения не устанавливают какого-либо «преимущества» исламских религиозных организаций по сравнению с другими религиозными образованиями (кстати, соответствие таких правил принципу «автономии» религиозных организаций - вопрос спорный). Справедливости ради следует отметить, что значительная часть этих положений была установлена на съезде представителей мусульманских общин, где был утвержден Устав УМК, после чего эти положения были включены в ЗСВ и приобрели высшую юридическую силу.

Хотя такие нормы добавляют публично-правовые элементы к отношениям между исламскими религиозными организациями, находящимися на разных ступенях организационной структуры, законодательство АР не признает публичных религиозных юридических лиц. Следовательно, все религиозные образования, включая исламские религиозные организации, считаются субъектами частного права.

Дифференциация титульных религий в других формах. В законодательной практике зарубежных стран распространены случаи закрепления роли той или иной религии в формировании истории, нравственности, государственности и других ценностей страны и народа. Например, в соответствующих актах стран отмечается «историческая роль ханафитского мазхаба ислама и православной церкви» в Казахстане [10], «исключительная историческая, государствообразующая и цивильная роль Сербской Православной Церкви в формировании, защите и развитии сербской нации» (ст.10) [13], считается, что Апостольская Церковь является «важной опорой духовной жизни и сохранения армянской нации» [9]. Преамбула Закона РФ «О свободе совести и религиозных объединениях» так же признает «особую роль православия в истории России, в становлении и 


\section{Цивільне, підприсмницьке, господарське та трудове право}

развитии ее духовности и культуры», а также выражает уважение христианству, исламу, буддизму, иудаизму и другим религиям, составляющим неотъемлемую часть исторического наследия народов России [11]. Ради объективности следует отметить, что в тексте самого Закона не предусмотрены какие-либо дополнительные права или привилегии для какой-либо из упомянутых или других религий. Тем не менее, отношение специалистов к содержанию указанного положения преамбулы неоднозначно [5]. Считаем, что закрепление в законодательных актах соответствующих положений об исключительной роли той или иной религии в формировании национально-духовных ценностей народа и традиций государственности, без установления каких-либо конкретных льгот и привилегий, не подрывает их формально-правовое равенство.

Учитывая вышеизложенное, можем заключить, что большинство государств, на конституционном уровне декларируя свою секулярность, а также равенство всех религий и религиозных образований, выделяют одно или несколько религиозных вероисповеданий под разными названиями (государственная, официальная, традиционная, публичная и т.д.). Считаем, что такая практика не должна привести к дискриминации по отношению к различным конфессиям и их корпоративным структурам. В соответствии с принципом равенства религиозных образований перед законом, создание в стране любых религиозных общин, их государственная регистрация, функционирование, управление их деятельностью и прекращение такой деятельности, должно осуществляться на основе единых законодательных актов, вне зависимости от их конфессиональной принадлежности, числа последователей, продолжительности существования и других признаков, которые могут повлиять на их правовой статус. Не должны быть предусмотрены какие-либо меры дискриминации в правовом статусе по признаку религиозной принадлежности ни на индивидуальном, ни на институциональном уровне; ни одна группа религиозных образований не должна пользоваться более благоприятными условиями, или наоборот, не должна оказаться в менее благоприятных условиях, а лица, способствующие такой дискриминации, должны быть привлечены к ответственности в соответствии с законом. Здесь главная задача государства заключается в обеспечении максимального использования возможностей этих религий во благо общества [29].

В то же время, по нашему мнению, закрепляя на конституционном уровне равенство всех религий перед законом и создав равные условия для функционирования их корпоративных структур, допустимо формальное декларирование исторических заслуг перед нацией и государством той или иной религии, а также ее роли в формировании национального самосознания.

\section{Литература}

1. Бурьянов С.А., Мозговой С.А. «Некоторые тенденции современных государственно-религиозных отношений в Российской Федерации» // «Право и политика». 2003 г. № 1. с. 63-67

2. Гражданский Кодекс Грузии// https://matsne.gov.ge/ru/d ocument/ download/31702/75/ru/pdf

3. Декларации о ликвидации всех форм нетерпимости и дискриминации на основе религии или убеждений // Принята резолюцией 36/55 Генеральной Ассамблеи ООН от 25 ноября 1981 года https://www. un.org/ruleoflaw/files/TH001.PDF

4. Журавский А. Религиозная традиция в условиях кризиса секуляризма// M., Континент. 2004, №120. https://magazines. gorky.media/ continent $/ 2004 / 120 /$ religioznaya-tradicziya-v-usloviyah-krizisa-sekulyarizma.html

5. Заключение Уполномоченного по правам человека в РФ «О проверке соответствия Федерального закона «О свободе совести и о религиозных объединениях» международно-правовым обязательствам Российской Федерации» // Российская газета. N 77, 22.04.99. 
6. Закон Австрии «О статусе корпораций»// «Vereinsgesetz», reenacted Aug. 28, $1951 / /$ BGBl. no. 233/1941, § 3 a

7. Закон АР “О свободе вероисповедание» (3СB) //e-qanun.gov.az

8. Закон Аитовской Республики «О религиозных общинах и ассосиациях»//http:// www.litlex.lt/Litlex/Eng/Frames/Laws/Documents/332.HTM

9. Закон Республики Армении "О свободе совести и религиозных организации»// www.legislationline.org/ru/documents/ $\frac{\mathrm{id} / 20260}{10}$

10. Закон Республики Казахстан“О религиозной деятельности и религиозных объединениях»// http://adilet.zan.kz/ rus/docs/Z1100000483

11. Закон РФ «О свободе совести и о религиозных объединениях»//

http://www.consultant.ru/document/ cons doc LAW 16218/

12. Закон Румынии № 489/2006«О свободе религии и общем статусе культов» // Legea nr. 489/2006 privind libertatea religioasă şi regimul general al cultelor // Publicată în Monitorul oficial Partea I. nr. 11/8.01.2007.

13. Закон Сербии «О церковях и религиозных общин»// https://www.upr-info.org/ followup/assessments//serbia/IRPP-Serbia.pdf

14. Кантеров И.Я. Новые религиозные движения. Введение в основные концепции и термины. Владимир. 2006. 136 с.

15. Конституция АзербайджанскойРеспублики // e-qanun.gov.az

16. Конституция Греции// http://hri.org/ docs/syntagma/

17. Конституция Исландии// https:// legalns.com/download/books/cons/ iceland. pdf

18. Конституция Королевства Норвегии // https://legalns.com/download/books/ cons/norway.pdf)

19. Конституция Аитовской Республики // https://e-seimas.lrs.lt/ portal/legalAct/lt

20. Конституция РФ// www.constitution. $\underline{\mathrm{ru} /}$

21. Куницын И. А. Правовой статус религиозных объединений в России: исторический опыт, особенности и актуальные проблемы. М. : Правосл. дело: отчий дом, 2000. 462 c.

22. Основной Закон Федеративной Республики Германия// http://vivovoco. astronet.ru/VV/LAW/BRD.HTM

23. Понкин И.В. Комментарий к некоторым статьям Федерального закона«О свободе совести и о религиозныхобъединениях". М., 2007. 120 с.

24. Ратманова Ю.С. Классификация и систематизация религиозных объединений в современной России: основные проблемы и риски применения»//Вестник Поволжского института управления. 2010, №4, c.70-74.

25. Себенцов Андрей. Противоречия в законодательстве о свободе совести //СОВА, Информационно-аналитический центр. 2004,/ http://www.sova-center.ru/religion/ publications/stateconfessional/2004/02/d1716/

26. Цыпин В.А. Церковное право. //Библиотека Киевской Духовной Академии/. Киев. 2012. 334 с..

27. Чаплин В. Выступление на научно-практической конференции «25 лет по пути свободы совести»//Материалы конференции. М., 2015. 248 с..

\section{На других языках}

28. Almond, Gabriel, R. Scott Appleby, and Emmanuel Sivan. Strong Religion: The Rise of Fundamentalism Around the World. Chicago, IL: University of Chicago Press. 2003. 292 p.

29. Cole W. Durham Jr. Relıgıous organizations and the rule of law in comparatıve perspectıve/ Journal The Review of Faith \& International Affairs, volume 8, 2010 - issue 2, p. 3-14 https://www.tandfonline.com/toc/rfia20/current

30. Cole W. Durham Jr. Freedom of Religion or Belief: Laws Affecting the Structuring of Religious Communities. 1999, // https:// www.refworld.org/pdfid/3e283bd01.pdf

31. Jonathan Fox. Civilizational Clash or Balderdash? The Causes of Religious Discrimination in Western and European Christian-Majority Democracies//Journal The Review of Faith \& International Affairs, Volume 17, 2019-issue 1. p..34-48. https://doi.org/10. $\underline{1080 / 15570274.2019 .1570754}$ 


\section{Цивільне, підприємницьке, господарське та трудове право}

32. Mary Ann Glendon. Makıng the case for religious freedom in secular societies // Journal of law and religion. Volume 33, 2018, 1ssue 3, p. 329-339/https://doi.org/10.1017/ jli.2019.3

33. Norman Doe. Law and Religion in Europe. A Comparative Introduction. Oxford University press. 2011, 306 p..

34. Robert J. Barro and Rachel M. McCleary, Which Countries Have State Religions? Harvard, 2005.

35. Đsgərov Ziyafət. Konstitusiya hüququ. Bak1 2011, 757 s. (Аскеров Зияфат. Констутиционное право (на азерб. языке).

Hasanov Simran Seyfaddin, Ph.D. in Law, lecturer at the Civil Law Department of the Law Faculty of Baku State University CERTAIN LEGAL ISSUES OF EQUALITY OF RELIGIOUS ENTITIES BEFORE THE LAW: COMPARATIVE ANALYSIS

The article discusses the practice of international and national legislations on the equality of religious entities before the law and related scientific and theoretical studies. The author studies the features of the formal legal equality of religious entities, based on a comparative analysis of the relevant legal acts of the Republic of Azerbaijan and several foreign countries, paying particular attention to certain points that impede such equality. The article also substantiates the impossibility and futility of ensuring the actual equality of religious entities and seeks ways out of the problems associated with different approaches of the state to various religions and their institutional structures. Particular attention is paid to the widely used in legal practice support of titular religions based on various classifications as there is no single position in the scientific and theoretical analysis of these problems. In conclusion, specific proposals are made to ensure the maximum formal legal equality of religious entities and to prevent discrimination against them.

Key words: religious entities, religious discrimination, formal equality, public legal entities, traditional religions, state religion. 